\title{
Infant Feeding, Weaning Practices and Oral Hygiene Status of 3 - 5-Year-Old Children with Severe Early Childhood Caries and Children without Caries in Kisumu, Kenya
}

\author{
Dorah Wassuna and Gladys Opinya \\ Department of Paediatric Dentistry, University of Nairobi, East Africa
}

Received: 眥April 13, 2018; Published: 眥 April 20, 2018

*Corresponding author: Gladys. Opinya, Department of Paediatric Dentistry \& Orthodontics; School of Dental Sciences; College of Health Sciences, University of Nairobi, P.O. Box 30197. 00100, East Africa

\section{Abstract}

Severe early childhood caries (Severe-ECC) is an aggressive form of dental caries in the primary dentition associated with specific patterns of dietary intake in young children. The objective of this study was to compare oral hygiene status of children aged 3 - 5 years with Severe Early Childhood Caries (ECC) and the oral hygiene of children without caries, infant feeding, and weaning practices.

One hundred and ninety-six children aged between stage between thirty-six to sixty months were selected using purposeful sampling.There were eighty-one children with severe early childhood decay were chosen from amongst the patients who had sought dental treatment at the dental clinic at the Nyanza Provincial General Hospital (NNPGH). However, 115 children who were caries free were selected from children attending the maternal child health clinic at NNPGH. Odds Ratio (OR) and 95\% Confidence Interval (CI) were used to estimate the strength of association between variables. The significance level was at a confidence interval of $95 \%$. Ninety-four (48\%), of the children, were breastfed or bottle-fed for 24 months or more. Among the children with severe ECC and children without caries $55(67.9 \%)$ and 70 (60.9\%) were exclusively breastfed respectively. In conclusios children with fair oral hygiene status were 148 (75.5\%) of whom 64 (79.1) had severe ECC while 84(73.0\%) had healthy teeth. The children with poor oral hygiene were in total 10 (5.1\%) of whom three had severe-ECC, and five had no decay. Children with Severe - ECC were fed on demand, and their oral hygiene was poor compared to children without caries also.

Keywords: Infant feeding habits; Weaning practices; Severe-ECC; Oral hygiene

\section{Introduction}

The definition of Early childhood caries (ECC) is that there is decay in one or more teeth bein on-cavitated or cavitated lesions. Also. Teeth missing due to caries, or filled tooth surfaces in any primary tooth in a child 71 months of age or younger.Children younger than three years of age, smooth surface caries is indicative of severe early childhood caries [1]. Severe ECC is associated with children from the age of 3 years through to 5 years, where there is a presence of one or more cavitated, missing (due to caries), or filled smooth surfaces in primary maxillary anterior teeth. Also, decayed, missing or filled score of $\geq 4$ (age 3), $\geq 5$ (age 4), $\geq 6$ (age 5) constitutes Severe - ECC [1]. ECC has been associated with bacteria in the streptococcus family in particular Streptococcus mutans and Streptococcus sobrinus another related pathogen is
Bifidobacteria. S, sobrinus, and Bifidobactira have been associated with recurrent decay in children with ECC [2]. However current research has reported more bacteria such as Streptococcus mutans, Streptococcus cristatus, Scardovia Wiggsiea, Veillonella parvula, and Actinomyces gerensceriae which have neem related to ECC [3]. However, Scardovia Wiggsiae has been found to be present in cases of severe-ECC in the absence of the other bacteria hence implicated as a pathogen of severe-ECC. The bacteria use the refined carbohydrates as substrates where they generate acid resulting in the demineralisation of the enamel of the deciduous teeth resulting in severe-ECC [4]. ECC can rapidly destroy the primary dentition of young children, and left untreated can lead to pain, infection and speech problems [2]. Specific feeding practices, such as bedtime 
bottle feeding, at will breastfeeding, while intake of sugary snacks and drinks regularly contribute to the development of ECC $[5,6]$. Studies have also shown that children with severe caries have more plaque and gingival inflammation than caries-free children [7].

\section{Materials and Methods}

One hundred and ninety-six children aged between 3 to 5 years were recruited for this study. Purposive sampling was done to select Eighty-one children with Severe - ECC chose from amongst the patients who had sought dental treatment at the dental clinic at the Nyanza Provincial General Hospital (NNPGH). However, 115 children who were caries free were selected from amongst the children attending the maternal child health clinic at NNPGH over a period of three months. Severe - ECC was defined as decayed, missing or filled a score of $\geq 4$ (age 3), $\geq 5$ (age 4), $\geq 6$ (age 5). A semi-structured questionnaire was administered to the caregiver in a face to face interview, and information was collected on infant feeding and weaning practices. The Intraoral examination was carried using dental mirrors and a Michigan 0 dental probe under natural light as the child sat on an ordinary upright chair. Silness and Löe (1964) plaque index were used to assess the oral hygiene status [8]. Six reference teeth 55, 51, 65, 75, 71, and 85 based on the FDI dental nomenclature plaque scores for each tooth were recorded from the distal, buccal, mesial, and lingual surfaces of six teeth[9].The recorded plaque scores for each reference tooth were added, together, and a mean score for was obtained by dividing the total derived score with the six teeth to give the mean plaque score.
The scores between 0.0 to 0.1 were excellent oral hygiene, 0.9 to 1.0 good, fair oral hygiene had a score of 1 to 1.9 , while a rating of between 2.0-3.0 was poor oral hygiene status. The inclusion criteria were that a child was 3-5 years of age, was medically healthy, and the parent or caregiver was willing to consent. The study design, protocol, and informed consent were approved by the Ethics and Research Committee of the University of Nairobi and Kenyatta National Hospital, Kenya. Data collected were coded and analyzed using SPSS version 17.0 (SPSS Inc, Chicago Illinois, USA) for Windows and Microsoft Office Excel 2007. Pearson's Chisquare tests were used to test the strength of association between categorical variables. To determine the significant relationship all exposure variables were associated with the dependent variable.

\section{Results}

There were 196 children aged between 3-5-years-old who were recruited into the study, eighty-one children with S - ECC $(41.3 \%)$ and $115(58.7 \%)$ without caries. The children's mean age was $4.1+0.6$ years, and it ranged between 3 and five years with a high proportion of the children (62.2\%) aged four years. There was a statistically significant difference in age distribution among children with Severe. ECC and children without caries $(\chi 2=28.36$, d.f $=2, p<0.001)$. The majority of the children with caries were aged four years $(84.0 \%)$ compared to those without caries $(47.0 \%)$. Gender distribution was comparable with boys slightly more (51.0\%) than girls (49.0\%) Table 1.

Table 1: Age and gender distribution of children with Severe - ECC and children without caries.

\begin{tabular}{|c|c|c|c|c|c|c|c|c|c|}
\hline \multirow{2}{*}{ Variables } & \multicolumn{2}{|c|}{ Total $(\mathrm{N}=196)$} & \multicolumn{2}{|c|}{$S-\operatorname{ECC}(n=81)$} & \multicolumn{2}{|c|}{ Without caries $(n=115)$} & \multirow{2}{*}{$\chi^{2}$} & \multirow{2}{*}{ d.f } & \multirow{2}{*}{$95 \%$ CL } \\
\hline & $\mathbf{N}$ & $\%$ & $\mathbf{n}$ & $\%$ & $\mathbf{n}$ & $\%$ & & & \\
\hline \multicolumn{10}{|c|}{ Age group } \\
\hline 3 years & 69 & 35.2 & 13 & 16.0 & 56 & 48.7 & \multirow{3}{*}{28.36} & \multirow{3}{*}{2.00} & \multirow{3}{*}{$\leq 0.001^{*}$} \\
\hline 4 years & 122 & 62.2 & 68 & 84.0 & 54 & 47.0 & & & \\
\hline 5 years & 5 & 2.6 & 0 & 0.0 & 5 & 4.3 & & & \\
\hline \multicolumn{10}{|c|}{ Sex of child } \\
\hline Male & 100 & 51.0 & 43 & 53.1 & 57 & 49.6 & \multirow{2}{*}{0.24} & \multirow{2}{*}{1.00} & \multirow{2}{*}{0.627} \\
\hline Female & 96 & 49.0 & 38 & 46.9 & 58 & 50.4 & & & \\
\hline
\end{tabular}

*Pearson's Chi-square

Out of 3,240 deciduous teeth for 81 children aged 3-5 years sixty one $1.9 \%$ of the teeth were missing due to decay hence 3179 teeth were examined of whom 605 (19\%) were decayed... The caries pattern was that the maxillary teeth were more affected compared to the mandibular teeth. In the mandible the least affected were the canines. However the first primary molar had high prevalence of between $71.6 \%-82.7 \%$. In the mandible the most affected teeth were the second deciduous molars which had a prevalence range of $88.9 \%-98.7 \%$ Figure 1 the study and they did not have ECC had been exclusively breastfeeding. However, 71 (36.2\%) out of the 196 respondents had had both breast/bottle feeding. Out of the seventyone, those who had breastfeeding supplemented with bottle feeding were $29(35.8 \%$ ), and they had severe ECC while $42(36.5 \%)$ out 115 of those without caries. Children who were exclusively bottle fed were eight of whom five $6.2 \%$ had severe ECC while three $2.6 \%$ did not have caries Figure 2. There were no differences in the methods of breastfeeding with a Pearson Chi-square $=3.51$, d. $\mathrm{f}=2, \mathrm{p}=0.173$ at $95 \%$ CL. 


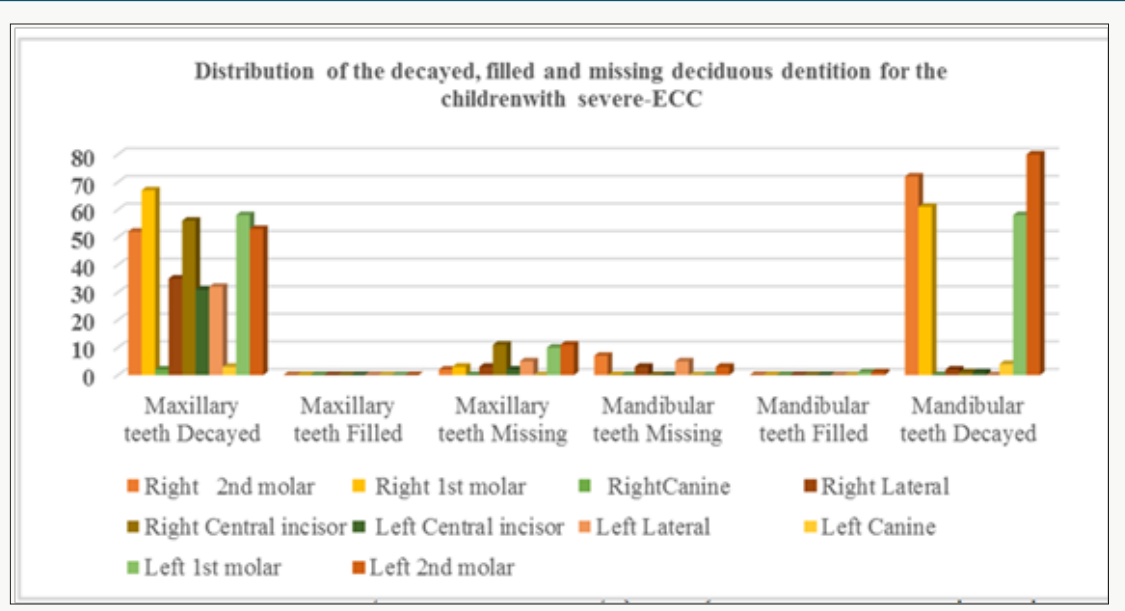

Figure 1.

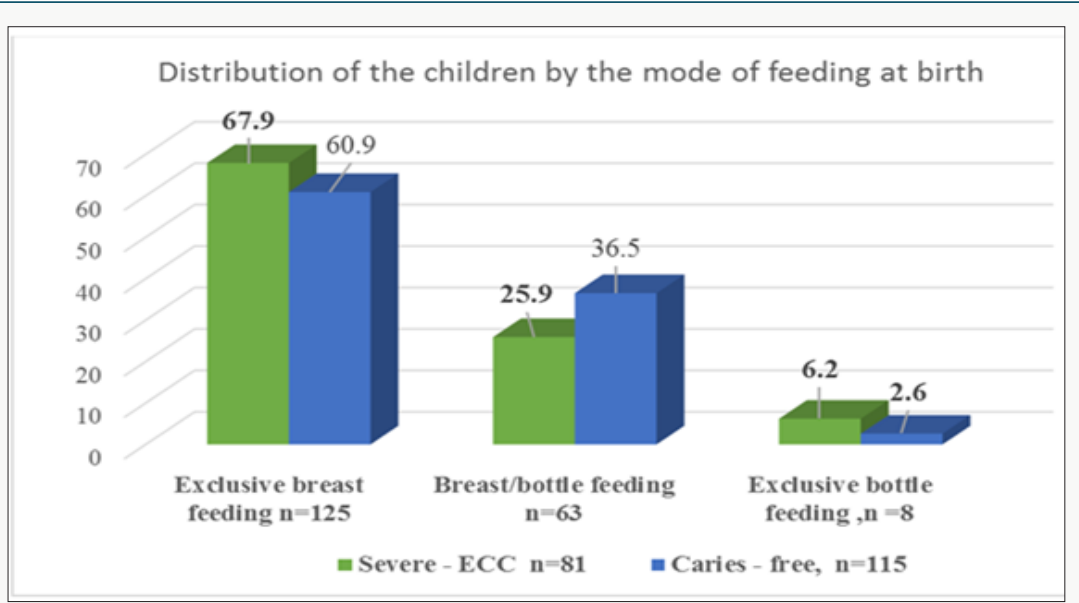

Figure 2: Percent distribution of children by the method of feeding in infancy and toddler stage.

Forty children, $20.4 \%$ had breast or bottle feeding or combined feeding for a $\leq 12$ month exclusively. Sixty-two (31.6\%) $12 \leq 24$ months while $94(48 \%)$, for $\geq 24$ months. There were $16(19.8 \%)$ of the children with severe-ECC had either breastfed or bottle fed or both for a time duration of $\leq 12$ months while those without decay were 24 (20.9\%). Similarly, 23 (28.4) children with severe-ECC had a duration of $12 \leq 24$ months while those without caries were 39
(33.9\%). Forty-two (51.9\%) and 52(45.2\%) of children with severe ECC and children without caries had respectively been breastfed for $\geq 24$ months, Figure 3. However, there were no significant differences between the breastfeeding period for the children with severe $-\mathrm{ECC}$ and those without decay with a Pearson Chi-square = 0.92, d.f $=2, p=0.630$ at $95 \%$ CL.

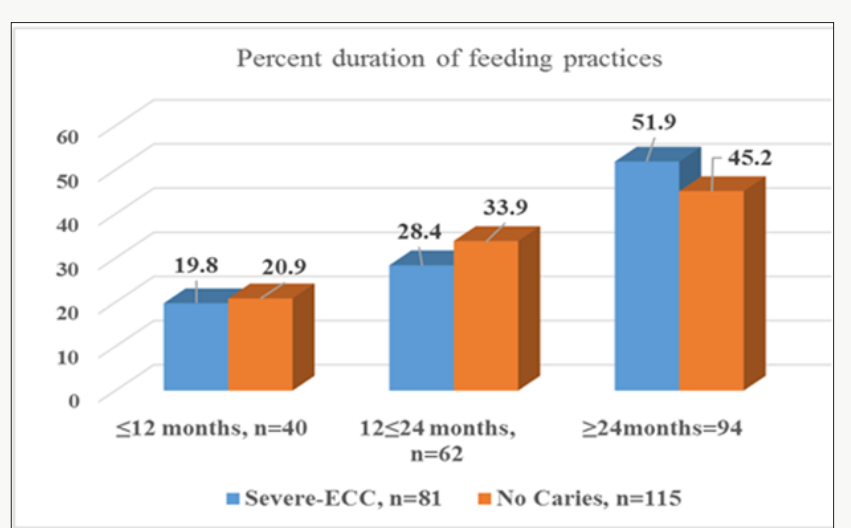

Figure 3: Percent distribution of duration of feeding practices in infants and toddlers with severe-ECC and those without decay aged 3-5 years. 
One hundred and twenty-five (63.8) children had exclusive breastfeeding while the remaining 71 (36.2\%) had either breastfeeding supplemented with bottle feeding or exclusive bottle feeding. The seventy71 who had breastfeeding and supplement or had exclusive bottle feeding the breast milk complement or supplement used was either cow's milk, porridge, milk mixed with porridge. Milk was the most common beverage bottle content for both groups of severe ECC and those without decay for 47 (66.2\%) out of the sixty-three children who had been bottle fed; six $8.5 \%$ had porridge, For eighteen (25.4\%) children the bottle content was a mixture of milk and porridge. Fifteen (18.5\%) children with severeECC had milk as the bottle content while $3(3.7 \%)$ the content was porridge and eight $((9.9 \%)$ children the bottle content was milk and porridge Figure 4 . There were no differences for the different practices about the breast milk complements or supplements with a Pearson Chi-square 1.39 d.f $=2 \mathrm{p}=0.500$ at $95 \%$ CL.

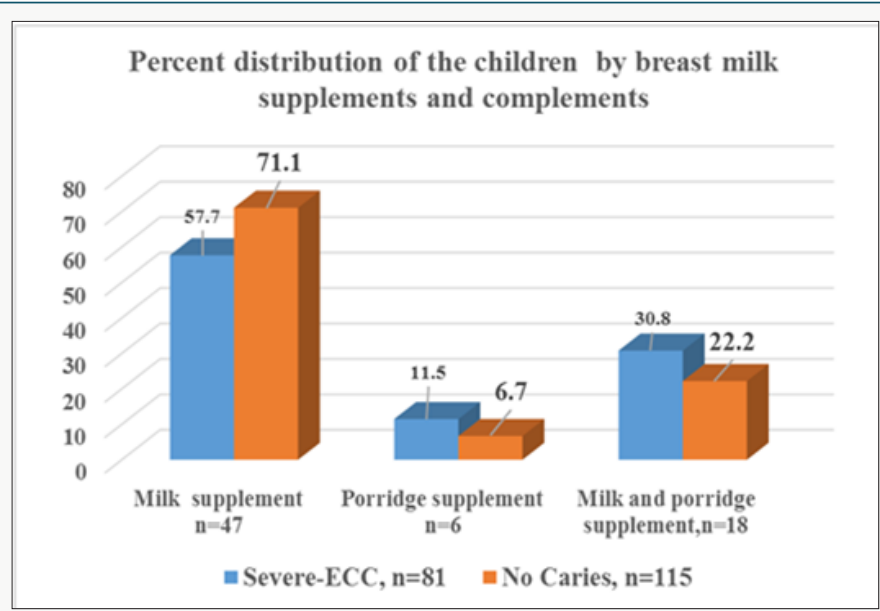

Figure 4: Percent distribution of children of on breast milk supplements and complements using the bottle.

Eighty-nine (45.4\%) children out of 196 were fed on demand while 107 (54.6\%) were not fed on demand. Out of the 81 children with severe ECC 54(66.7\%) were fed on demand compared to 35 (30.4\%) out of 115 who did not have decay. However, 27 (33.3\%) children out of 81 of those who had severe-ECC were not fed on demand. Similarly, 80 (69.6\%) of the 115 who did not have decay were not fed on demand Figure 5. The difference was statistically significant with a Pearson Chi square $=25.17$ d.f $=1.0, p \leq 0.001$ at 95\%CL.

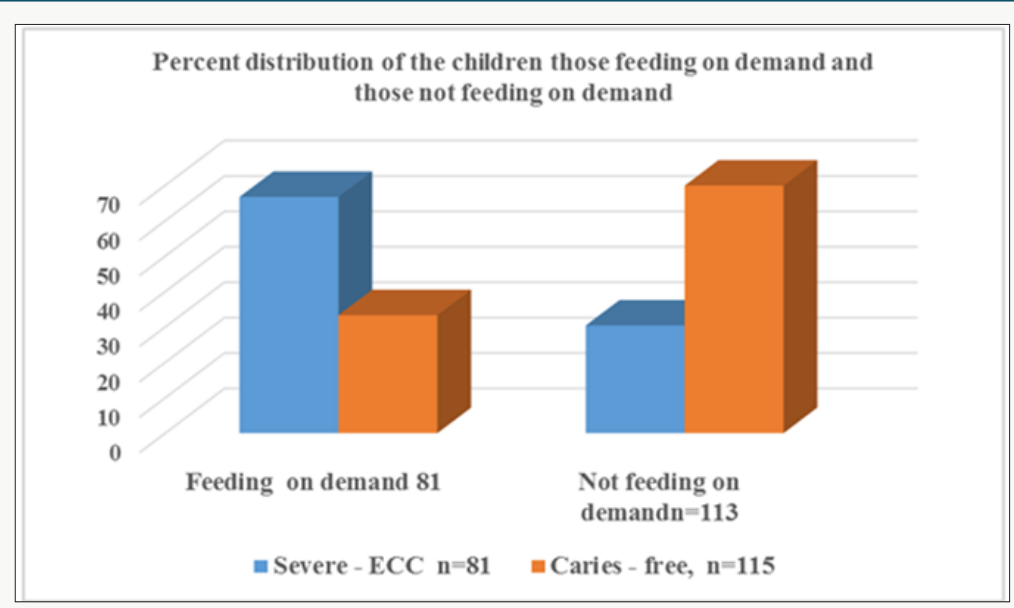

Figure 5: Percent children of children who were fed on demand and those not feeding on demand for those with severe-ECC and those without decay.

Six $(3.1 \%)$ children had excellent oral hygiene, and they were from the group of children without decay. Children with good oral hygiene were $32(16.3 \%)$ of which 10 (12.3) were from the group with severe-ECC and 22 (19.!\%) from the group without dental decay.The oral hygiene of 148 (75.5\%) children had affair oral hygiene, those with severe-ECC were 64 (79\%) out of 81 , and those without decay 84 (73\%) out of 115 had fair oral hygiene. Only ten $(5.17 \%)$ had poor oral hygiene of out of whom - $(8.6 \%)$ had severe -ECC and three (2.6\%) did not have decay, Figure 5. There was significant the difference in the oral hygiene status of children with S - ECC and children without caries with a Pearson Chi-square $2=9.18$, df1, $p=0.027$ ). 


\section{Discussion}

Severe early childhood caries (Severe-ECC) is an aggressive form of dental caries in the primary dentition associated with specific patterns of dietary intake in young children [1.10]. Most of the children 125(63.8\%)were breastfed while $71(36.2 \%)$ were put on breastmilk compliments/ supplements early in infancy and some of them stayed on the bottle after the second birthday. Mothers in Kenya are encouraged to practice exclusive breastfeeding [8-14]. It is documented that nursing mothers in Kenya have a high breastfeeding frequency pattern occurring in $93 \%$ of mothers wherein a twenty-four hour period in the daytime the infant according to UNICEF a mother is recommended to breastfeed three times a day. However, Kenyan mothers are encouraged to breastfeed as much as possible and some of them breastfeed on demand as many as seven times in the daytime and five times at night on demand [11-13]. In the current study $63 \%$ of the children were exclusively breast fed and this finding is in agreement with the national value of $61 \%$ breastfeeding mothers who practice exclusive breastfeeding at least the first six moths of infancy. In order to enhance good oral health and the general health of and infant there is a need to provide information on the benefits of good oral hygiene for the breasting mother and the breastfed infant or toddler so that frquency of nocturnal at will breastfeedin is minimised. Thse may reduce the sustrate which the cariogenic bacteria require to produce acid and it will also reduce the production of the plaqure which holds the acid close to the enamel resulting in enamel dimineralisation. The oral health information and education may be incorporated in the prenatl clinics as information available to the expectantnt mothers.

It is currently documented that exclusive on demand breastfeedng may lead to severe- ECC which is a debilitating oral disease condition and it may be a confouder to malnutrition of the child who is in pain is unable to jew food properly and this may lead to nutritional deficiencis. The deficieneces may interfere with the proper pysical and mental growth and development of the child.
Secondly vital nutional deficiences may lower the immunity of the child thus making the infant and toddler with severe -ECC to be vulnerable to early childood diseases.

The children who had exclusive breastfeeding were $63.7 \%$ of the study group and the breastfeeding period was $\geq 24$ months which was slightly higher than the reported duration of exclusive breastfeeding $[11,13]$. Children who were fed on demand were $45.6 \%$ of the sample size out of whom $66.7 \%$ had severe ECC, and the difference was significant with a Pearson Chi-square $p \leq 0.001$.At will breastfeeding/ bottle-feeding on demand pauses a particular risk to the deciduous dentition which has low mineral content and thin enamel. In the current study out of 81 children with severeECC 55(67.9\%). Out of the ninety-four children with prolonged breastfeeding 49(51.9\%) had severe-ECC and had beyond twentyfour months. Though breastfeeding is good for the child, the nocturnal breastfeeding and the high frequency in the daytime which is twice what is recommended by UNICEF the stagnation of milk around the newly erupted teeth may be fermented by the anaerobic bacteria thus producing large quantities of acid. There is a need to encourage the mothers in breastfeeding but give them the knowledge to clean the infant's mouth and to avoid nocturnal breastfeeding [11-13].

The dietary weaning practices included the use of a bottle where the breast milk supplement or complement was, milk, porridge or porridge mixed with milk. The introduction of a bottle has been associated with diarrheal disease in early childhood. The early childhood diseases further weakens the child's immunity resulting in a vicious circle of disease and malnutrition in early childhood which may result in a child not being able to thrive.

Majority of the children with Severe -ECC were fed on demand $(66.7 \%)$ compared to those without caries $(30.4 \%)$, and this was statistically significant Pearson chi-square with $\mathrm{p} \leq 0.001$. The difference in the oral hygiene status of children with Severe - ECC and children without caries were substantial with a Pearson Chisquare $=2=9.18$, df $2 \mathrm{p}=0.027$ ).

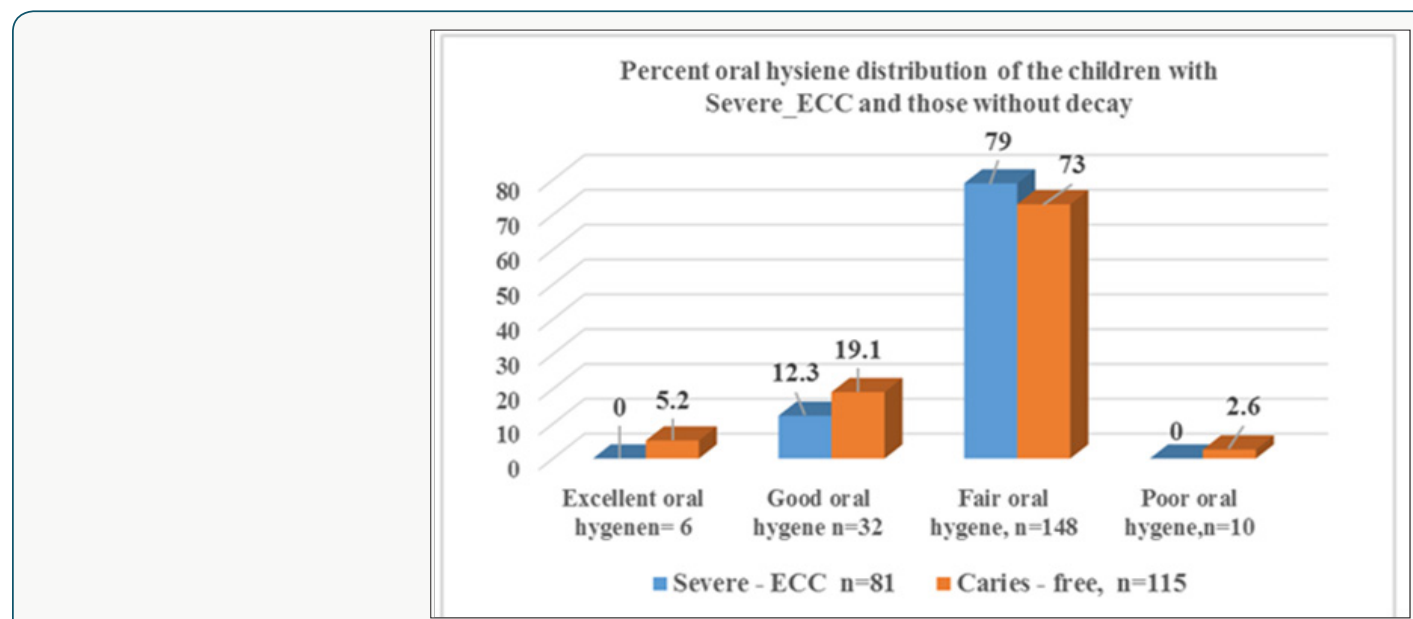

Figure 6: Oral hygiene status for children with severe-ECC and those without caries. 
The most critical period of feeding at will has been reported to be twelve months. The period of twelve months is when most of the deciduous teeth with a thin and poorly mineraised enamel are fully erupted in the mouth. In the presence of the virulent anerobic bacteria Streptococcus Mutans Scardovia Wiggsiae the denttion is dimineralised $[3,14]$. The sustrate and bacteria presence are confounded by the factor that at one year there are no oral hygiene paracties for the toddler and the vist to the dentist is not yet hence emanel demineralisation may progress unabated Figure 6.

The feeding on demand results in having acid producing bacteria resulting in prolonged periods of a low $\mathrm{pH}$ resulting in the demineralization of the dentition. Recent research has incriminated the bacteria Scardovia wiggsiea as an anew pathogen which has been found at the sites of severe EC lesions in the absence of other pathogens which had previously been associated with severe ECC $[2,3]$. Ultimately, prolonged exposure of the teeth in the acidic environment causes dental caries. There were differences in the oral hygiene status of the children with severe-ECC compared with those who had no caries which was statistically significant.

A study in Saudi Arabia has reported similar findings where caries was associated with a high presence of debris [6]. The high caries debris could probably be due to poor oral hygiene practices among children with severe- ECC. National Oral health survey has reported poor utilisation of oral health services where a sample of 2,126 individuals age $5-15$, nine hundred and only three $(46.7 \%)$ had never visited an oral health facility. Out of those who had never visited a dentist, $57.7 \%$ were from the rural community where the services were scarce due to distance or resources were not available to provide oral health services for both the children and the adults $[15,16]$.

The challenge may be overcome by having information and education incorporated in the well established maternal health, and well-child clinics on simple preventive remedied for good oral health practices to minimize plaque deposits and severe ECC.The preventative measures may ensure that the children have healthy teeth for mastication and digestive processes would also improve the quality of life for the children.

\section{References}

1. American Academy of Paediatric Dentistry (2003) The Definition of Early Childhood Caries (ECC).

2. CA Palmer, R Kent, CY Loo, CV Hughes, E Stutius, et al. (2010) Diet and Caries-associated Bacteria in Severe Early Childhood Caries. J Dent Res 89 (11): 1224-1229.

3. Tanner AC, Mathney JM, Kent RL, Chalmers NI, Hughes CV, et al. (2011) Cultivable Anaerobic Microbiota of Severe Early Childhood Caries. J Clin Microbiol 49(4): 464-474.

4. Milnes AR (1996) Description and epidemiology of nursing caries. J Public Health Dent 56(1): 38- 50.

5. Ismail AR (1998) Prevention of early childhood caries. Community Dent Oral Epidemiol 26(1 Suppl): 49S-61S.

6. Sohn W, Burt BA, Sowers MR (2006) Carbonated soft drinks and dental caries in the primary dentition. J Dent Res 85(3): 262-266.

7. Kanasi E, Dewhirst FE, Chalmers NI, Kent R, Moore A, et al. (2010) Clonal analysis of the Microbiota of Severe Early Childhood Caries. J Dent Res 44(5): 485-497.

8. Silness J, Loe H (1964) Periodontal disease in pregnancy. II. Correlation between oral hygiene and periodontal condition. Acta Odontol Scand 22: 121-135.

9. Federation Dentaire Internationale Two Digit Notation.

10. Hallett K, O'Rourke PK (2006) Pattern and severity of early childhood caries. Community Dent Oral Epidemiol 34(1): 25-35.

11. Ministry of Health: Child health Kenya - Demographic and Health Survey 2008-09.

12. Leah N Mututho, Willy K Kiboi, Patrick K Mucheru (2017) Factors associated with exclusive breastfeeding in Kenya: a systematic review Int J Community Med Public Health 4(12): 4358-4362.

13. (2014) Kenya National Bureau of Statistics: The 2014 Kenya Demographic and Health Survey (2014 KDHS).

14. Feldens CA, Rodrigues PH, de Anastácio G, Vítolo MR, Chaffee BW (2018) Feeding frequency in infancy and dental caries in childhood: a prospective cohort study. Int Dent J 68: 113-121.

15. (2015) Ministry of Kenya: Kenya National Oral Health Survey Report 2015.

16. Ngatia EM, Imungi JK, Muita JW, Nganga PM (2001) Dietary patterns and dental caries in nursery school children. East Afr Med J 78(12): 673-677.

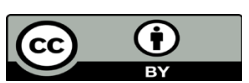

This work is licensed under Creative Commons Attribution 4.0 License

To Submit Your Article Click Here:

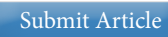

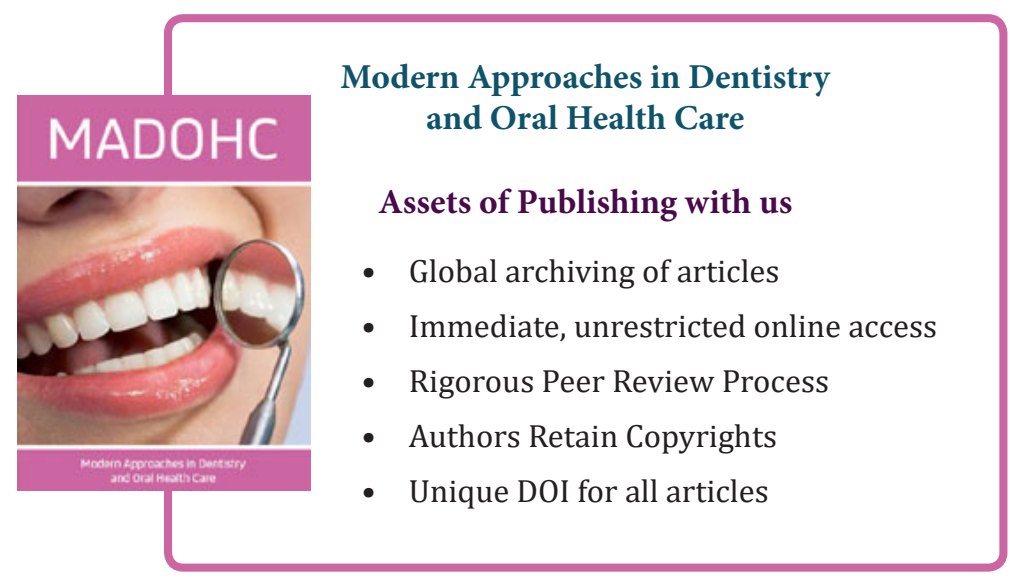

DOI: 10.32474/MADOHC.2018.02.000128 